\title{
Os Principais Assuntos de Auditoria Importam? Uma análise de sua associação com o Gerenciamento de Resultados
}

Kleyverson Leonardo dos Santos

https://orcid.org/0000-0002-9411-8725

Renan Bittencourt Guerra

https://orcid.org/0000-0002-3041-6686

Vagner Antônio Marques

https://orcid.org/0000-0001-7210-4552

Elizeu Maria Júnior

https://orcid.org/0000-0002-8228-5980

\author{
E-mail: kleyverson12@hotmail.com
}

E-mail: renan@bttcontabilidade.com.br

E-mail: vagner.marques@ufes.br

E-mail: elizeu.maria@ufes.br

\section{Resumo}

Objetivo: Analisar a relação entre os Principais Assuntos de Auditoria (PAAs) reportados e a prática de gerenciamento de resultados das empresas brasileiras.

Método: A amostra de pesquisa foi composta por 96 empresas listadas no IBRX 100 cujos dados foram coletados na Comissão de Valores Mobiliários (CVM) e na base de dados COMDINHEIRO, no período compreendido entre 2016 e 2017, utilizando estatística descritiva e análise de regressão com dados em painel.

Resultados: Os tipos de PAAs predominantes foram: Recuperabilidade dos ativos, Contingências e Reconhecimento de receitas, respondendo, conjuntamente, nos anos de 2016 e 2017, por 58\% e 66\%, respectivamente. Observou-se uma associação positiva e significativa entre a quantidade de PAAs e os accruals e receitas discricionárias e uma associação negativa e significativa entre a quantidade de PAAs reportados e a proxy de gerenciamento de resultados pelas operações através das despesas discricionárias. Contribuições: Os resultados têm implicações no debate sobre o tema, em especial, sobre as práticas de contadores, auditores e reguladores, pois apresentam insigths relevantes sobre a associação entre a divulgação de PAAs e as proxies de gerenciamento de resultados pelos accruals e pelas operações reais, evidenciando a importância da divulgação dos PAAs como red flag para manipulação de dados contábeis. Palavras chave: PAAs, Gerenciamento de Resultados, Auditoria. 


\section{Introdução}

A busca por mecanismos que reforcem a segurança nos investimentos é crescente entre investidores que atuam no mercado de capitais e que estão inseridos no ambiente corporativo, sobretudo os minoritários (Choi \& Wong, 2007). E, apesar da condição de proprietário, o que o acionista investidor observa é a possibilidade de os gestores, contratados para a tomada de decisão que maximize o valor da firma para quem detém a propriedade, tomarem decisões cotidianas para o funcionamento da empresa que priorizem seus interesses pessoais (Ross, 1973; Brickley, Smith, \& Zimmerman, 2016). Segundo Jensen \& Meckling (1976), esse desalinhamento entre acionistas e gestores denomina-se problema de agência. A gestão do negócio fica sob a responsabilidade de gestores contratados com o objetivo de maximizar o valor da empresa. Ocorre que, dadas a característica oportunista dos indivíduos e a incompletude dos contratos, os gestores podem utilizar-se da assimetria informacional - uma vez que estes têm maior acesso à informação do que o acionista - para atender aos seus interesses em detrimento dos objetivos pelos quais foram contratados (Williamson, 1979; Jensen \& Meckling, 1994).

Entre os diversos problemas de agência existentes, destacam-se as práticas de gerenciamento de resultados por parte dos gestores. Esse termo é definido na literatura contábil como sendo a utilização do poder discricionário dos gestores, de modo que resulte em escolhas contábeis enviesadas ou, até mesmo, de alteração do nível de operações com vistas a atingir resultados específicos desejados, podendo resultar tanto positiva quanto negativamente nos resultados divulgados.

Dessa forma, visto que o acionista não tem acesso às informações diárias sobre a companhia, o auditor tem o papel de fornecer ao investidor e demais stakeholders a verificação acerca da fidedignidade das demonstrações contábeis, reduzindo a assimetria informacional. Por conseguinte, na relação entre gestores e acionistas, o auditor possui papel de mitigar os conflitos de agência entre gestor eacionistas (Brown, Beekes, \& Verhoeven, 2011).

Diante disso, os órgãos reguladores, com o intuito de melhorar a qualidade da auditoria, emitiram em 2016 a Norma Brasileira de Contabilidade - NBC TA 701, que versa a respeito do julgamento acerca dos principais assuntos de auditoria identificados no decorrer da execução do trabalho de auditoria das demonstrações contábeis. Em termos gerais, estabelece que os auditores destaquem em campo próprio do relatório de auditoria os assuntos críticos identificados ao longo da execução do trabalho. Trata-se de uma informação com potencial de utilidade aos diversos usuários, tendo em vista que esses assuntos podem estar associados aos problemas de agência mencionados, possibilitando uma maior avaliação de risco por parte dos investidores e demais partes interessadas, inclusive os próprios auditores (Marques \& Souza, 2017).

Segundo Marques e Souza (2017), os principais assuntos de auditoria (PAAs) reportados em 2017 pelas empresas que compuseram o Ibovespa no último trimestre de 2016 foram: (i) recuperabilidade de ativos, (ii) contingências, (iii) reconhecimento de receitas e (iv) projeções de resultados futuros. Observase, entre esses PAAs, que, por tratarem de temas diretamente ligados à flexibilidade das normas contábeis e/ou estimativas contábeis, podem ser utilizados ou estarem associados ao gerenciamento de resultados. No âmbito internacional, Church, Davis e McCraken (2008) reiteraram a importância da opinião do auditor e sua comunicação com investidores e potenciais investidores, indicando, inclusive, uma maior eficiência do mercado. No entanto, Segal (2017) relata em seu estudo que o nível de gerenciamento de resultados não foi afetado pela evidenciação opinativa do auditor.

Nesse contexto, o presente estudo buscou responder à seguinte pergunta: Qual a relação entre os Principais Assuntos de Auditoria (PAAs) e a Prática de Gerenciamento de Resultados das empresas listadas na $[\mathbf{B}]^{3}$ ? O objetivo geral do estudo foi analisar a relação existente entre os tipos de PAAs divulgados pelas empresas de auditoria e a prática de gerenciamento de resultados. $\mathrm{O}$ estudo, de natureza descritiva, documental e quantitativa, utilizou como amostra 96 companhias listadas no IBRX 100. Os dados foram coletados na Comissão de Valores Mobiliários (CVM) e referiram-se ao período de 2016 e 2017, que compreendeu os dois primeiros anos de vigência da norma. A análise foi realizada a partir da estatística descritiva, de testes de diferenças entre as médias e da análise de regressão com dados em painel. 
Devido à ausência de trabalhos acadêmicos nacionais que explorassem a relação entre as hipóteses de gerenciamento de resultados e os PAAs emitidos pelos auditores, este artigo propõe-se ao preenchimento dessa lacuna, buscando em pesquisas internacionais resultados e considerações que contribuam para a análise e interpretação dos seus achados, uma vez que a NBC TA 701 segue o padrão internacional de auditoria.

Além disso, dada a relevância das prescrições normativas, que visam a uma comunicação mais transparente entre os auditores e os usuários das informações contábeis, este trabalho dedicou-se ao esclarecimento dos efeitos das normas de auditoria, tanto no campo teórico quanto no empírico, para o mercado de capitais.

Complementarmente, o auditor é visto dentro da organização auditada como uma espécie de orientador de normas contábeis, controles internos e de generalidades corporativas (Beattie, Fearnley \& Brandt, 2000). Portanto, torna-se relevante mensurar e analisar o grau de interação entre as proxies de gerenciamento de resultados e as obrigações dos auditores em reportarem os assuntos que consideraram mais relevantes durante o processo de auditoria. Segundo Dechow e Skinner (2000), os reguladores detectam a ocorrência de práticas de gerenciamento de resultados nos relatórios contábeis e que o uso desses métodos é mais evidente em firmas com baixo nível de estrutura de governança. No entanto, o presente estudo procura contribuir na avaliação do impacto normativo em relação aos PAAs emitidos pelos auditores. Em relação a essa norma em estudos internacionais, apesar de não encontrar relação entre o gerenciamento de resultados e os PAAs reportados, Segal (2017) enfatiza que esse tipo de evidenciação contribui para a transparência entre os gestores e stakeholders.

Além da presente introdução, este artigo está dividido em quatro seções. Na seção dois, apresentouse o referencial teórico com a discussão sobre a Hipótese de Eficiência (HME) e o papel do auditor, as hipóteses relacionadas ao gerenciamento de resultados, bem como as motivações e implicações da divulgação dos PAAs pelas empresas, inclusive apresentando resultados de estudos anteriores. Na seção três, apresentaram-se os procedimentos metodológicos adotados. Na seção quatro, realizaram-se a análise e a discussão dos resultados. E, na última seção, apresentaram-se as considerações finais, implicações e limitações do estudo, bem como sugestões para pesquisas futuras.

\section{Referencial Teórico}

\subsection{Hipótese de Eficiência de Mercado e o Papel da Auditoria para o Mercado de Capitais}

A Hipótese de Eficiência de Mercado foi apresentada por Fama (1970), sob a premissa principal de que os preços dos ativos são reflexos das informações contábeis disponíveis aos usuários. Dessa forma, o conjunto de informações disponíveis (públicas e privadas) reflete os valores dos ativos e, consequentemente, no valor da empresa.

Fama (1970) classifica a eficiência de mercado em três categorias: fraca, semiforte e forte. Em sua forma fraca, os preços são definidos pelo conjunto de informações históricas. Na semiforte, os preços são refletidos pelas informações passadas (históricas) e correntes. Por fim, na forma forte, os preços dos ativos são função das informações históricas, correntes e informações de caráter privado.

Nesse contexto, a utilização de métodos contábeis que garantam a fidedignidade da informação pode resultar em um aumento da qualidade informacional, garantindo que os investidores disponham de informações relevantes para tomada de decisões (Barth, Landsman \& Land, 2008).

No entanto, de acordo com a teoria da Agência, existe a possibilidade iminente de conflitos de agência, pois, como o gestor possui mais acesso às informações do que os acionistas, ele pode utilizar essa diferença no nível de informações para alcançar objetivos pessoais específicos, de modo diferente do que os acionistas esperariam (Jensen \& Meckling, 1976). 
Tal possibilidade existe, pois, de acordo com Jensen e Meckling (1994), os agentes possuem as seguintes características: i) avaliadores; ii) maximizadores; iii) criativos e iv) possuidores de desejos ilimitados. Dessa forma, os autores afirmam que os agentes, ao agirem como maximizadores, avaliam o ambiente em que atuam sempre buscando priorizar o próprio bem-estar, atendendo aos seus desejos sempre renováveis; e utilizam a sua criatividade para que as restrições existentes sejam superadas e seus objetivos sejam alcançados. Diante de tais condições, as escolhas contábeis originadas dos agentes podem ser tendenciosas e influenciar negativamente as decisões dos acionistas e usuários dos relatórios contábeis (Beaver, 1998).

Para mitigar os conflitos de agência, são adotadas práticas de governança corporativa, que consistem em um conjunto de mecanismos que contribuem para assegurar a fidedignidade dos relatórios financeiros, e práticas de controle interno (Cohen, Krishnamoorthy, \& Wright, 2004). Entre esses mecanismos, destacase a auditoria externa das companhias, que tem o objetivo de avaliar a fidedignidade das demonstrações contábeis, proporcionando maior credibilidade às demonstrações contábeis e servindo como um ente representativo dos interesses dos shareholders (Marques \& Souza, 2017).

Segundo Kothari, Ramanna \& Skinner (2010), os acionistas fundamentam suas decisões a partir do conjunto de informações, inclusive das demonstrações contábeis fidedignas e atestadas pelos auditores. Para isso, a auditoria possui ferramentas específicas que são capazes de apontar se determinadas práticas dos administradores são definidas como conservadoras, neutras ou fraudulentas, descumprindo ou seguindo as práticas contábeis vigentes (Dechow \& Skinner, 2000).

Nesse contexto, a manipulação das informações contábeis resulta em uma diminuição da proteção do investidor normativamente garantida pelos órgãos reguladores. Isso se dá tendo em vista que a proteção aos stakeholders limita o grau de liberdade e/ou incentivo do gestor em manipular as informações contábeis, reduzindo, assim, a possibilidade de mascarar o real desempenho da empresa (Leuz, Nanda \& Wysocki, 2003).

Para Vladu, Amat, \& Cuzdriorean (2017), o crescimento das manipulações contábeis praticadas pelos gestores decorre principalmente de três fatores: (1) aumento anormal de recebíveis, (2) aumento de endividamento e (3) decrescimento de vendas. Além disso, do ponto de vista ético, os autores acrescentam que os gestores podem justificar o uso de tais métodos contábeis como se estivessem seguindo as "boas práticas" da contabilidade, já que as normas baseadas em princípios não determinam como os agentes devem mensurar e reconhecer atos e fatos contábeis, mas, sim, que devem realizar o julgamento mais adequado para a escolha dos métodos que atendam às características qualitativas da informação contábil.

\subsection{Hipóteses de Gerenciamento de Resultados}

O gerenciamento de resultados, apesar de ter inúmeras definições com diferentes abrangências, consiste, em linhas gerais, na utilização de escolhas contábeis e operacionais por parte dos gestores, a fim de atender a resultados específicos (da firma ou dos próprios agentes). Tais escolhas podem prejudicar a tomada de decisões por parte de stakeholders em função da falsa percepção da situação econômica da entidade, ou, até mesmo, influenciar resultados contratuais que dependem dos números contábeis (Alzoubi, 2016).

Isso pode acontecer porque, de acordo com Watts e Zimmerman (1986), os gestores tendem a agir de maneira oportunista. Essa característica idiossincrásica propensa aos indivíduos indica a primazia pela busca de vantagens individuais (Williamson, 1979). Dessa forma, os gestores, frente a situações com liberdade decisória, podem optar pelo método contábil mais conveniente a si mesmos, promovendo uma maximização do seu bem-estar em detrimento de outros envolvidos, podendo prejudicar a sustentabilidade da empresa e os principais (acionistas) a quem representam. Esse processo se dá, em parte, pela assimetria informacional entre as partes, pois o agente possui mais informações a respeito da firma do que o principal. Sendo assim, as escolhas contábeis refletem o grau de mensuração dessas oportunidades (Jensen \& Meckling, 1976; Queiroz \& Almeida, 2017). De acordo com Watts e Zimmerman (1986), as bases para a adoção de práticas de gerenciamento de resultados decorrem de três hipóteses: i) Hipótese do Plano de Incentivo(HPI); ii) Hipótese do Grau de Endividamento(HGE) e; iii) Hipótese dos Custos Políticos (HCP). 
A HPI é a prática de escolhas contábeis e/ou operacionais realizada pelos gestores que resulta em formas de manipulação dos números contábeis e/ou do nível das operações. Pode ser apresentada de forma a reduzir perdas (para aumentarem o lucro corrente), aumentar as perdas (quando alcançada uma meta de lucro) ou, até mesmo, suavizar os resultados, reduzindo uma volatilidade dos índices financeiros (Scott, 2011). Dessa forma, se a remuneração dos gestores estiver atrelada ao resultado da empresa, esses gestores podem procurar agir de forma oportunista e buscar uma antecipação de lucros futuros para o período corrente, manipulando os números contábeis (Gaver, Gaver, \& Austin, 1995). Lewellen e Rosenfeld (1987) concluíram que os gestores com tempo limitado em seus cargos tendem a limitar os gastos futuros, objetivando resultados de curto prazo mais expressivos e, consequentemente, maior remuneração no momento presente. Kauhanen e Napari (2012) demonstram que executivos em níveis hierárquicos mais altos possuem mais incentivos a remuneração em decorrência dos resultados apresentados.

A HGE consiste na utilização de escolhas contábeis e/ou operacionais para maquiar a proporcionalidade de dívida em relação ao capital próprio, justificadas com o objetivo de cobrir números contábeis para que não haja quebra de cláusulas contratuais (conhecidas como debt covenants) de empréstimos tomados. De acordo com HassabElnaby (2006), essas cláusulas reduzem os custos de agência do banco, restringindo a capacidade da companhia tomadora do empréstimo de adotar medidas que diminuam o valor presente de sua dívida pendente. Dessa forma, essa hipótese apresenta a possibilidade de o gestor realizar a manipulação dos dados contábeis a fim de que contratos não sejam violados, não incorrendo em quebras contratuais (Watts \& Zimmerman, 1986). Nesse contexto, Dichev e Skinner (2002) encontraram evidências que possibilitaram a conclusão de que os gestores se utilizam de prerrogativas contábeis a fim de evitar essas violações contratuais.

Por fim, a HCP é baseada na premissa de que as transações são uma competição política de transferência de riquezas. Em linhas gerais, essa hipótese prevê que as companhias sujeitas à investigação do governo ou ao maior monitoramento dos stakeholders podem ter incentivos para gerenciar seus resultados, com o intuito de reduzir a probabilidade de transferências de riqueza impostas (Makar \& Alam, 1998). Assim, considerando que determinadas firmas são mais observadas nesse processo de transferência de riquezas, Watts e Zimmerman (1986) destacam que os gestores se utilizam de ferramentas contábeis que reduzem os lucros e/ou os lucros esperados. Setyorini e Ishak (2012) afirmam que, na possibilidade de que os acionistas percebam um maior crescimento em relação a períodos anteriores, haveria uma maior expectativa em relação aos dividendos, incidindo, dessa forma, em custos políticos de transação de recursos. Um exemplo disso se dá no estudo de Makar e Alam (1998), em que os autores apontam a possibilidade de redução dos resultados da firma pela utilização de accruals com o intuito de diminuir os custos políticos associados às investigações governamentais.

Arruñada (2010) observa que os relatórios financeiros são elaborados pelos agentes (gestores). Logo, de forma a assegurar a confiabilidade das informações contidas nesses relatórios, a auditoria externa caracteriza-se como um dos mecanismos capazes de mitigar o risco de gerenciamento de resultados, sejam eles por accruals ou por operações reais.

Por conseguinte, dada a iminência de comportamento oportunista do agente e a discricionariedade dos gestores na aplicação das normas, a regulação quanto à apresentação das demonstrações contábeis, tem envidado esforços no sentido de melhorar a qualidade e a transparência das informações contábeis apresentadas. 


\subsection{Principais Assuntos de Auditoria: Motivações e Implicações}

De acordo com Ishikawa e Bezerra Júnior (2002), a auditoria tem como principal finalidade examinar se as demonstrações contábeis da empresa auditada estão em conformidade com as normas de contabilidade vigentes. Isso posto, a opinião quanto à fidedignidade dessas demonstrações é apresentada no relatório de auditoria. Seu objetivo é explicitar as bases utilizadas na análise, bem como os assuntos que os auditores julgarem relevantes destacar para uma compreensão mais acurada da real situação patrimonial e financeira da entidade.

Nesse sentido, verifica-se que a auditoria tem função mitigadora do conflito de agência, reduzindo a assimetria informacional, uma vez que permite aos usuários interessados nas informações financeiras da entidade verificar a veracidade das demonstrações contábeis da companhia (Becker, Defond, Jiambalvo, \& Subramanyam, 1998).

No entanto, apesar de a literatura evidenciar que ainda não há um contrato ótimo para eliminar o conflito de agência, pressupondo então que a regulação, a governança corporativa e a auditoria não são capazes de suprimir tal conflito, sua evolução pode reduzir a probabilidade de ocorrência de erros e fraudes (Di Pietra, McLeay, \& Ronen, 2014).

Dessa forma, foram empreendidos esforços para melhorar a qualidade dos trabalhos dos auditores. No contexto brasileiro, o Conselho Federal de Contabilidade (CFC) aderiu aos padrões internacionais de normas contábeis (IFRS - International Financial Reporting Standards - IFRS), resultando também na conversão das normas brasileiras de auditoria às normas internacionais de auditoria (International Standards Auditing -,ISA).

Nesse contexto, em 2010, a NBC TA 200 aprovada pelo CFC entrou em vigor. Esse documento trata dos objetivos gerais do auditor em conformidade com as normas brasileiras e internacionais de auditoria, expondo como objetivo da auditoria aumentar o nível de confiança nas demonstrações contábeis por parte dos usuários. Isso possibilitado por meio de uma opinião emitida pelo auditor em seu relatório sobre se as demonstrações contábeis apresentadas pela entidade estão em conformidade com uma estrutura de relatório financeiro aplicável.

Mais recentemente, buscou-se melhorar a regulação através da NBC - Norma Brasileira de Contabilidade, TA - Técnica de Auditoria (NBC TA) 701, que acompanha a adoção de padrões contábeis internacionais. Essa norma surge em decorrência da International Standards Auditing 700 - ISA, que norteia os auditores a respeito da evidenciação da opinião do auditor sobre quais assuntos foram mais relevantes durante o trabalho de verificação das demonstrações contábeis, assim como a posterior evidenciação dessa opinião em parágrafo específico em seu parecer de auditoria (Matos, Santos, Rodrigues, \& Leite, 2018).

Desse modo, a NBC TA 701 exige, desde 2016, a manifestação dos auditores em área específica no seu parecer de auditoria sobre quais foram os Principais Assuntos de Auditoria (PAAs), ou seja, quais assuntos exigiram maior atenção durante o trabalho de auditoria, devendo ser disponibilizados e informados em parágrafo específico (em inglês, Key Audit Matter ou Critical Audit Matters). Assim, os auditores apresentam quais foram os assuntos que exigiram atenção significativa na realização de auditoria e reportam esses temas em seus relatórios, mencionando as motivações para incluí-los, assim como a explicação de como esses itens foram tratados nas demonstrações contábeis (Marques \& Souza, 2017).

Essa norma tem o objetivo de tornar o relatório de auditoria mais transparente para os interessados, comunicando possíveis fatores de risco para os stakeholders, inclusive os auditores. Sendo assim, essa norma, de acordo com Bédard, Gonthier-Besacier e Schatt (2014), por meio das divulgações expressadas pelos auditores, contribui com a discussão sobre o conteúdo informacional dos relatórios contábeis e avança para uma melhoria em relação à transparência e prestação de contas dos gestores e da companhia auditada. No entanto, os autores não encontraram, no mercado financeiro francês, evidências de que os relatórios dos auditores melhorassem a qualidade informacional de auditoria, medida por meio de gerenciamento de resultados. 
Além disso, Brasel, Doxey, Grenier e Reffett (2016) afirmam que esses apontamentos sobre pontos críticos e importantes de auditoria podem servir para alertar os investidores e demais stakeholders a respeito de distorções nas demonstrações contábeis. Procurando investigar a responsabilidade dos auditores em casos de fraudes financeiras julgadas por um júri, os autores encontraram evidências de diminuição da probabilidade de veredictos por negligência dos auditores quando os problemas julgados foram expressados pelos profissionais de acordo com a norma internacional. Isso aponta que o relatório dos auditores pode contribuir para uma maior percepção dos stakeholders em relação à previsibilidade de certos tipos de distorções. Por conseguinte, o ato de reportar PAAs atribui tanto à gestão quanto aos auditores responsabilidade para uma maior transparência, possibilitando que os usuários das informações decidam com maior assertividade, tendo uma asseguração razoável quanto à veracidade desse conteúdo (Brasel, Doxey, Grenier, \& Reffett, 2016; Marques \& Souza, 2017; Boolaky \& Omoteso, 2016).

De qualquer forma, nos estudos voltados para verificar a aceitação de tal norma pelos profissionais de auditoria, observa-se uma concordância por parte desse corpo de profissionais acerca da importância em se mencionar quais foram os assuntos mais relevantes. Desse modo, é possível, inclusive, reforçar as diferenças entre as responsabilidades da gestão e a responsabilidade de auditoria, além de explicar de qual maneira esse assunto mencionado foi tratado durante o trabalho de auditoria (Dantas, Barreto, \& Carvalho, 2017).

\section{Procedimentos Metodológicos}

O presente estudo classificou-se como descritivo, documental e com abordagem quantitativa. Utilizouse análise de conteúdo para categorizar os PAAs reportados pelos auditores, seguindo-se as categorias propostas por Marques e Souza (2017). Essa categorização se fez necessária com o intuito de quantificar e avaliar os PAAs reportados de auditoria por meio das técnicas propostas por este estudo, tratando-se de análise descritiva e inferencial com análise de regressão e testes de diferenças entre as médias.

A amostra deste estudo foi composta pelas 96 empresas que compuseram o IBrX100 da [B] ${ }^{3}$. Essa amostra intencional e não probabilística foi escolhida por reunir as companhias com maior desempenho médio das cotações dos ativos de maior negociabilidade e representatividade no mercado acionário brasileiro.

A coleta de dados foi realizada no sítio da CVM e na base de dados COMDINHEIRO e compreende os anos de 2016 e 2017. A análise desses dois exercícios se justifica, pois foram os primeiros anos da intitulação dos PAAs, conforme vigência da NBC TA 701 no ano de 2016.

\subsection{Medidas do Gerenciamento de resultados}

De acordo com Sincerre, Sampaio, Famá e Santos (2016), a literatura apresenta inúmeros instrumentos para mensurar os níveis de gerenciamento de resultado, e a maioria desses modelos se baseia nas acumulações (accruals), que consistem na diferença entre o lucro líquido e o fluxo de caixa operacional líquido. Nesse contexto, os accruals podem afetar os lucros da empresa, uma vez que são fundamentados em pressupostos e estimativas contábeis (Paulo, 2007). 
As proxies de gerenciamento de resultados utilizadas neste estudo foram realizadas a partir dos modelos constantes na Tabela 1. Para a proxy de gerenciamento de resultados por accruals, foi utilizado o modelo de Jones com ROA, adaptado por Kothari, Leone \& Wasley (2005), em que os autores afirmam que os modelos discricionários podem, de fato, detectar manipulações financeiras conforme Modelo 1. A diferença entre esse modelo e o de Jones Modificado, proposto por Dechow, Sloan e Swenney (1995), consiste na utilização de um novo controle para a estimação das acumulações não discricionárias, levando em consideração as variáveis receita líquida (RL), contas a receber (CR) e a variável de retorno sobre os ativos (ROA). A utilização da variável ROA para a estimativa dos accruals se justifica, uma vez que foi a mais consistente após análise de resíduos. Também foi utilizado o modelo de Roychowdhury (2006) para medir o gerenciamento de resultado das atividades operacionais, sendo que tal metodologia também foi utilizada por autores na literatura científica, tais quais Zang (2012), Badertscher (2011), Cohen e Zarowin (2010) e Rodrigues, Paulo e Melo (2017).

Tabela 1

Modelos utilizados para estimação das proxies de gerenciamento de resultados

\begin{tabular}{|c|c|}
\hline $\begin{array}{l}\text { Tipo/Nomes das proxies de } \\
\text { gerenciamento de resultados (EM) }\end{array}$ & Equação \\
\hline \multicolumn{2}{|l|}{ Por accruals } \\
\hline Jones Modificado com ROA (1) & $\begin{array}{l}A D_{i}=A T_{i} A D_{i}=A T_{i_{-}} A N D_{i} A N D_{i} ; A D_{i}=\varepsilon_{i} A D_{i}=\varepsilon_{i} \\
A T_{i}=\alpha_{1}\left(\frac{1}{A t_{i t-1}}\right)+\alpha_{2}\left(\frac{\Delta R L_{i}-\Delta R C_{i}}{A t_{i t-1}}\right)+\alpha_{3}\left(\frac{I m o b_{i}}{A t_{i t-1}}\right)+\alpha_{4} R O A_{i}+\varepsilon_{t}\end{array}$ \\
\hline \multicolumn{2}{|l|}{ Pelas atividades } \\
\hline DVGA discricionárias (2) & $\begin{array}{l}\frac{D V G A_{i}}{A t_{i t-1}}=\beta_{0}+\beta_{1}\left(\frac{1}{A t_{i t-1}}\right)+\beta_{2}\left(\frac{R L_{i}}{A t_{i t-1}}\right)+\varepsilon_{t} \\
D V G A D i s c r_{i}=D V G A_{i}-D \widehat{V G A}_{1}\end{array}$ \\
\hline FCO's discricionários (3) & $\begin{array}{l}\frac{F C O_{i}}{A t_{i t-1}}=\beta_{0}+\beta_{1}\left(\frac{1}{A t_{i t-1}}\right)+\beta_{2}\left(\frac{R L_{i}}{A t_{i t-1}}\right)+\beta_{3}\left(\frac{\Delta R L_{i}}{A t_{i t-1}}\right)+\varepsilon_{t} \\
\text { FCODiscr }_{i}=F C O_{i}-\widehat{F C O}\end{array}$ \\
\hline Receitas Discricionárias (4) & $\begin{array}{l}\frac{\Delta C R_{\mathrm{i}}}{A t_{i t-1}}=\beta_{0}+\beta_{1}\left(\frac{\Delta R L_{i}}{A t_{i t-1}}\right)+\varepsilon_{\mathrm{t}} \\
\text { CRDisCr }_{\mathrm{i}}=C R_{\mathrm{i}}-\widehat{C R}_{\mathrm{t}}\end{array}$ \\
\hline
\end{tabular}

Nota: $A T_{i} A c c r u a l s$ totais mensurados pela diferença entre o $L L_{i}$ : Lucro Líquido do Exercício e o $F C O_{i}$ Fluxo de Caixa Operacional. Além disso, mensuraram-se os Accruals totais pela diferença entre o CGL;: Capital de Giro Líquido e a Deprec Depreciação, Amortização e Exaustão, em que o CGL= [(Ativo Circulante -Disponível) - (Passivo Circulante - Empréstimos e Financiamentos - Impostos a Pagar)]; $A t_{i t-1}$ :Ativo total do ano anterior; $R L_{i}$ : Receita líquida; $I m o b_{i}$ : Imobilizado; $A N D_{i}$ : Accruals Não Discricionários; $A D$ : Accruals Discricionários; $D V G A$ : Despesas com vendas, gerais e administrativas: $C R$ : Saldo de contas a receber.

Para responder à pergunta formulada, o estudo utilizou-se de regressões de cross-section ano/setor para a estimação das proxies de gerenciamento de resultados. Já para analisar o efeito dos PAAs sobre o gerenciamento de resultados, utilizou-se a análise de dados em painel a partir do Modelo 5. 
A variável PAA foi utilizada com o intuito de verificar a associação entre os PAAs reportados da empresa auditada e as proxies de gerenciamento de resultados utilizadas. Considerando que os PAAs referem-se a assuntos críticos e potenciais riscos aos stakeholders (inclusive o auditor), espera-se que empresas com maiores quantidades de PAAs tenham maiores níveis de gerenciamento de resultados. Para se chegar ao modelo final, foi realizada uma série de testes e modelagens, inclusive por tipos de PAAs, porém o que apresentou maior adequação foi o demonstrado no Modelo 5 com o logaritmo do total de PAAs reportados no ano.

As variáveis Remuneração dos Executivos (Rem), Nível de Endividamento (NivEnd) e Tamanho da Empresa (Tam) são controles necessários e estão associadas às hipóteses de gerenciamentos de resultados discutidas na Seção 2. A variável Remuneração dos Executivos tem a finalidade de verificar o desempenho da companhia. Tal consideração é explicada pela premissa de que, com maiores remunerações, o gestor irá buscar uma maior valorização da firma (Sonza \& Kloeckner, 2014), pois, quando a hipótese da remuneração do gestor estiver atrelada aos resultados da entidade, haverá uma propensão do agente em agir de maneira oportunista e antecipar os lucros a fim de obter maiores ganhos, com a possibilidade de manipular os números contábeis (Gaver L L., 1995). A variável Nível de Endividamento (NivEnd) é determinada pela proporção da dívida da empresa, a divisão do total de passivos (obrigações) pelo total de ativos (direitos). Nesse sentido, procura-se fundamentar a hipótese dos Custos Políticos ao vincular-se o nível da dívida com as práticas de gerenciamento de resultados, indicando a possibilidade de que os gestores se utilizam de prerrogativas contábeis para suavizar os lucros e/ou lucros esperados. A variável Ativo busca mensurar o tamanho da empresa e sua relação com o gerenciamento de resultados. Companhias que possuem maiores ativos totais têm menores índices de gerenciamento de resultados, uma vez que possuem controles internos robustos, além de mecanismos de governança corporativos melhor estruturados (Kim, Liu \& Rhee, 2003).

Além disso, utilizaram-se outras quatro variáveis de controle: (i) Estrutura de Propriedade, (ii) Tipo de Auditor (Big4 ou Não Big4), (iii) Segmento Econômico e (iv) Nível de Governança. A variável Estrutura de Propriedade (EstrProp) é baseada na proporção de membros independentes no Conselho de Administração. Essa variável pressupõe que quanto menor for o número de conselheiros das companhias, maior será a propensão da utilização da discricionariedade por parte dos gestores.

A variável dummy Big Four (Big4) controla a presença, ou não, de grandes firmas de auditoria, conhecidas atualmente como Big Four, sendo elas: Delloitte Touche Tohmatsu, Ernst \& Young, KPMG e Pricewaterhousecoopers. Tal variável é relevante em termos de gerenciamentos de resultados, uma vez que o estudo de Almeida e Almeida (2009) evidencia que os clientes das Big Four apresentam menores índices de gerenciamento de resultados.

A variável dummy Segmento Econômico (SegEcon) foi incluída com o intuito de verificar se existe alguma diferença entre os segmentos em que as empresas da amostra estão classificadas em relação à opinião dos auditores. Essa classificação é tida como: Bens Industriais, Consumo Cíclico, Consumo não Cíclico, Financeiro e Outros, Materiais Básicos, Utilidade Pública e Outros. Ademais, a utilização dessa variável configura a relação entre os assuntos de auditoria e as atividades exercidas pelas empresas.

A variável dummy Nível de Governança (NivGov) foi considerada a partir da classificação segundo os critérios da $[\mathrm{B}]^{3}$, sendo dividida em Tradicional, Nível 1, Nível 2 e Novo Mercado. A utilização dessa variável é justificada de acordo com o estudo de Marques e Souza (2017), em que os autores afirmam que quanto maior for o nível de governança corporativa da empresa, menor será a propensão de se emitir um PAA da categoria.

A avaliação do efeito dos PAAs sobre as proxies de gerenciamento de resultados utilizadas (modelos de 1 a 4) foi realizada a partir do Modelo 5. A variável explicativa de interesse (PAA) foi testada com diversas especificações (dummy, proporção, etc.), porém, apenas com a utilização do logaritmo do total de PAAs reportados, o modelo como um todo apresentou significância estatística, logo os resultados que não foram significativos não foram apresentados. 
Modelo 5

$$
\begin{aligned}
E M_{i t}=\alpha+\beta_{1} & \ln \left(\text { PAA }^{\prime} s_{i t}\right)+\beta_{2}\left(\text { Rem }_{i t}\right)+\beta_{3}\left(\text { NivEnd }_{i t}\right)+\beta_{4}\left(\text { Tam }_{i t}\right) \\
& +\beta_{5}\left(\text { NivEnd }_{i t}\right)+\beta_{6}\left(\text { Tam }_{i t}\right)+\beta_{7}\left(\text { EstrProp }_{i t}\right)+\sum_{i=1}^{4} D_{i j} \text { Big } 4^{4} \\
& +\sum_{i=1}^{9} D_{i j} \text { SegECon }+\sum_{i=1}^{4} D_{i j} \text { NivGov }+\varepsilon_{i t}
\end{aligned}
$$

Em que:

$E M_{i t}:$ Proxy de Gerenciamento de Resultados por Accruals e Operacionais reportados na tabela 1: (i) DACC - Accruals Discricionários, (ii) DSGA - Despesas Discricionárias, (iii) DPROD - Produção Discricionária, (iv) DFCO - Fluxos de Caixa Discricionários e (v) DREC - Receitas Discricionárias. PAA's:

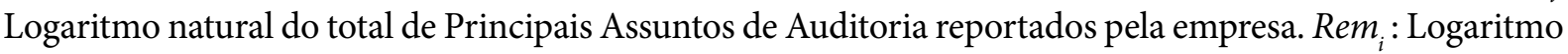
natural da remuneração dos executivos reportado no formulário de referências. $A t_{i}$ : Logaritmo natural do ativo total das empresas. NivEnd: Logaritmo natural do total de passivos dividido pelo total de ativos. EstrProp: $_{i}$ logaritmo natural da proporção de membros independentes no conselho. Big4: Variável dummy que assume valor 1 quando a empresa é auditada por uma Big4 e 0 para as demais. SegEcon: Variável dummy que assume valor 1 quando a empresa participa do iésimo segmento econômico e 0 para as demais. NivGov: Variável dummy que assume valor 1 quando a empresa participa do iésimo nível diferenciado de governança e 0 para as demais.

Ressalta-se que foram aplicados quatro modelos neste estudo que buscaram responder à pergunta acerca da evidência da relação entre os principais assuntos de auditoria e a hipótese de gerenciamento de resultados. Para tanto, os modelos consideraram: i) accruals; ii) fluxo de caixa operacional; iii) despesas discricionárias e; iv) receitas discricionárias.

\section{Resultados e Análises}

\subsection{Características dos PAAs reportados}

Inicialmente, analisou-se a distribuição dos PAAs reportados nos anos de 2016 e 2017, conforme a Figura 1. Verificou-se que os relatórios dos auditores das empresas participantes da amostra reportaram 349 PAAs em 2016 e 330 em 2017.

Além disso, observou-se que, na distribuição de frequência dos PAAs reportados nos anos estudados, existe uma concentração média de 2 a 4 assuntos por empresa. Marques e Souza (2017) afirmam que a quantidade de PAAs analisada isoladamente pode não representar um problema, mas permite considerar que, mesmo que inicialmente esses parágrafos não se apresentem de forma problemática, as informações contábeis endossadas pelos auditores podem ser utilizadas pelos usuários como parâmetros para tomadas de decisão. 


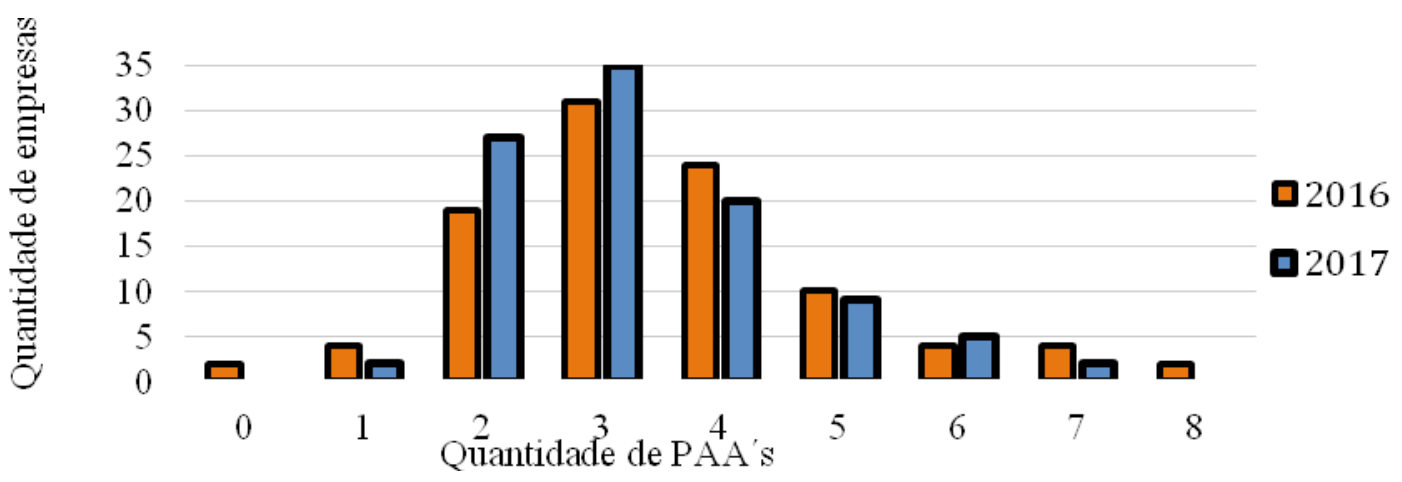

Figura 1. Distribuição de frequência por quantidade de PAAs emitidos por empresa

Fonte: dados da pesquisa

Posteriormente, analisaram-se os tipos de PAAs emitidos (Figura 2). Observa-se que somente três tipos de considerações dos auditores (recuperabilidade dos ativos, contingências e reconhecimento de receitas) contemplam 58\% das observações nos parágrafos destinados às PAAs em 2016, enquanto esses mesmos assuntos se fazem presentes em 66\% dos parágrafos dos auditores em 2017. Esses dados corroboram a pesquisa de Colares, Alves e Pinheiro (2018), uma vez que os autores analisaram as empresas listadas na B3 no exercício de 2016 e concluíram que os assuntos "reconhecimento de receitas", "provisões" e "impairment de ativos" foram os temas mais recorrentes dos auditores das companhias.

É importante mencionar que as categorias de PAAs acima citadas contemplam estimativas e/ou questões que podem estar associadas contabilmente à prática de gerenciamento de resultados, seja por accruals ou pelas atividades operacionais da entidade. Por isso, segundo Marques e Souza (2017), tal observação representa um ponto de atenção e risco da auditoria na verificação da fidedignidade das informações contábeis, uma vez que a discricionariedade presente na regulamentação das normas contábeis proporciona liberdade de escolha aos agentes que podem desfavorecer a qualidade da informação.
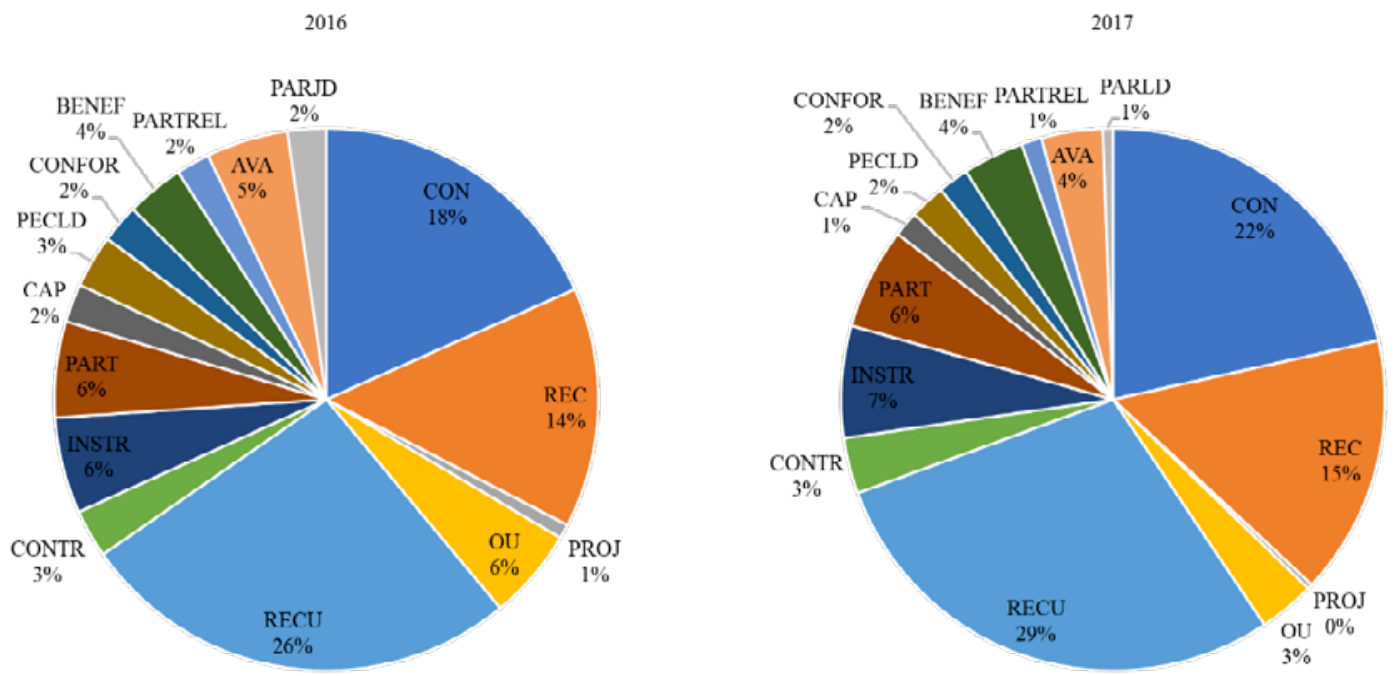

Nota: AVA - Ativos biológicos/Valor justo/Ágio; BENEF - Benefícios pós-emprego; CAP - Capitalização de gastos no ativo; CON - Contingências; CONFOR - Riscos relacionados à conformidade com leis e regulamentos; CONTR - Controles internos e tecnologia da informação; INSTR - Instrumentos financeiros; PARLD - Processos administrativos instaurados/ Recuperação judicial/Distratos; PART - Participação societária; PARTREL - Partes relacionadas; PECLD - Provisão para créditos de liquidação duvidosa; PROJ - Projeção de resultados futuros para a realização de ativos; REC - Reconhecimento de receitas; RECU - Recuperabilidade dos ativos; e OU - Outros.

Figura 2. Distribuição dos tipos de PAAs reportados nos anos de 2016 e 2017

Fonte: dados da pesquisa 
No que se refere à distribuição de frequência dos PAAs por empresas de auditoria (Figura 3), verificase que as empresas auditadas por Big Four reportaram mais PAAs. Esse resultado pode ser justificado em função do fato de que as Big Four realizaram maior quantidade de auditorias do que as demais empresas prestadoras desse serviço, representando $92,5 \%$ do total de relatórios analisados. Dessa maneira, esperase que quanto maior a quantidade de empresas auditadas, maior será a propensão a se reportar PAAs.

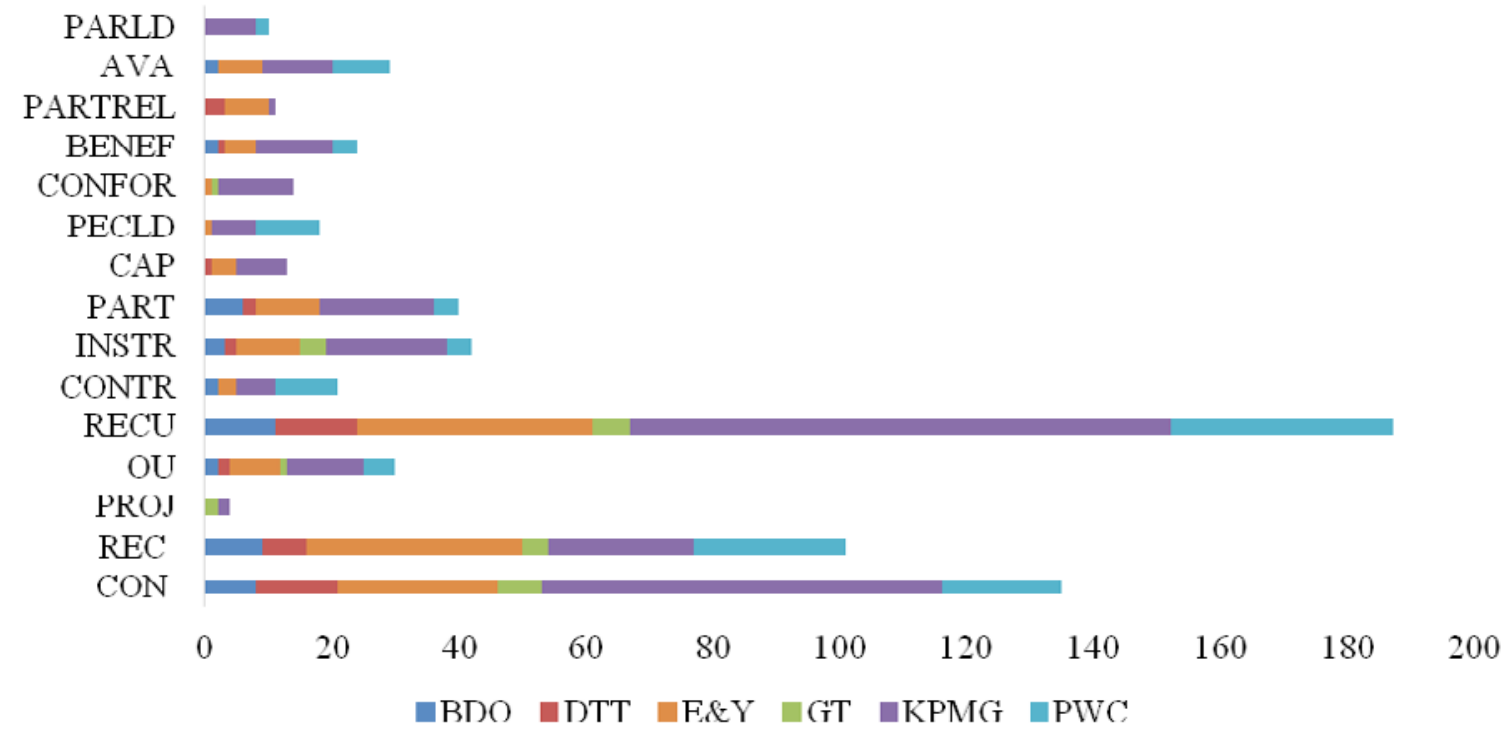

Nota: AVA - Ativos biológicos/Valor justo/Ágio; BENEF - Benefícios pós-emprego; CAP - Capitalização de gastos no ativo; CON - Contingências; CONFOR - Riscos relacionados à conformidade com leis e regulamentos; CONTR - Controles internos e tecnologia da informação; INSTR - Instrumentos financeiros; PARLD - Processos administrativos instaurados/ Recuperação judicial/Distratos; PART - Participação societária; PARTREL - Partes relacionadas; PECLD - Provisão para créditos de liquidação duvidosa; PROJ - Projeção de resultados futuros para a realização de ativos; REC - Reconhecimento de receitas; RECU - Recuperabilidade dos ativos; e OU - Outros. Empresas de auditoria Big Four: DTT - Deloitte Brasil Auditores Independentes; E\&Y - Ernst \& Young Auditores Independentes; KPMG - KPMG Auditores Independentes; PWC - PricewaterhouseCoopers Auditores Independentes. Empresas de auditoria não Big Four: BDO - BDO RCS Auditores Independentes; e GT - Grant Thornton Auditores Independentes.

Figura 3. Distribuição dos tipos de PAAs por empresas de auditorias nos anos de 2016 e 2017

Fonte: dados da pesquisa

Complementarmente, em consonância com o estudo de Colares et al. (2018), verificou-se que, entre as empresas de auditoria Big Four, a KPMG foi a que mais reportou PAA's médios, emitindo 3,5 parágrafos por empresa auditada. Entretanto, quando analisadas as empresas de auditoria que não são Big Four, verificou-se que as empresas Grant Thorton e BDO emitiram, em média, respectivamente, 4,16 e 3,75 PAAs por relatório, obtendo valores superiores à KPMG.

No que se refere à análise de PAA's reportados por empresa/nível de governança corporativa (Figura 4) no período de 2016 e 2017, verificou-se que as companhias classificadas no nível Tradicional apresentaram uma média de 3,38 PAAs por empresa. Já as empresas do Nível 1, entre as quatro categorias de nível de governança, apresentaram maiores números médios de PAAs, com emissão de 3,93 PAAs por empresa. As companhias de Nível 2, por sua vez, apresentaram média de 3,46 PAAs por empresa. Por fim, as empresas categorizadas como Novo Mercado emitiram, em média, 3,21 PAAs por empresa. 


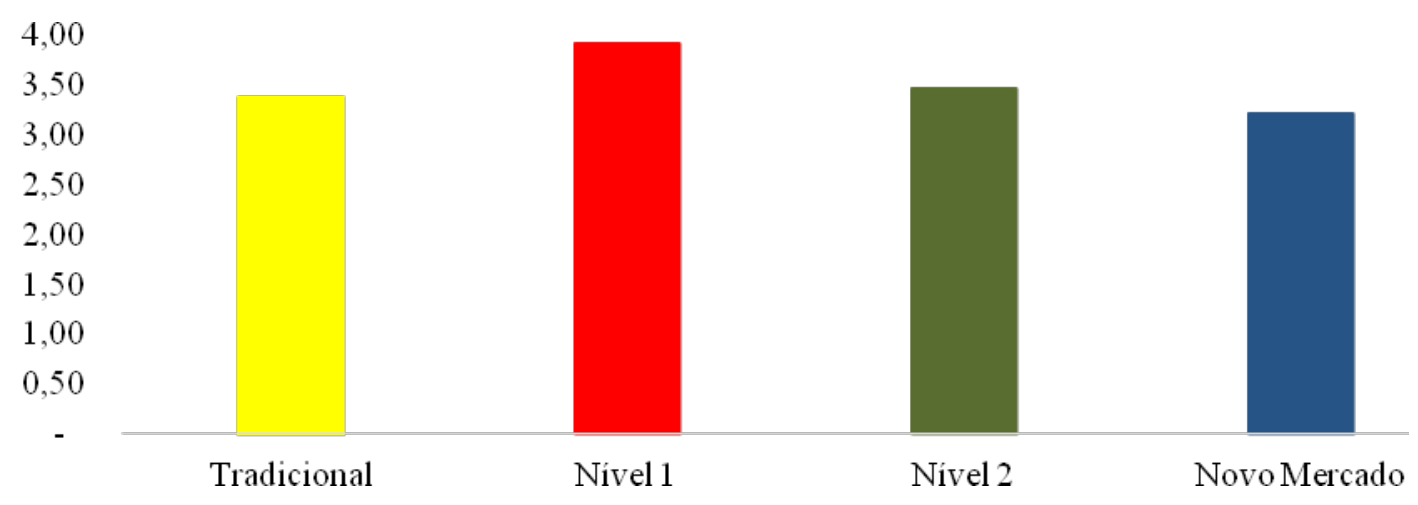

Figura 4. Média de PAAs reportados por Empresa/Nível de Governança

Fonte: dados da pesquisa

Observa-se, portanto, que as empresas de Nível 1 e Nível 2 de Governança Corporativa emitem mais PAAs médios. Essa afirmativa corrobora a afirmação de Scott (2011), em que o autor aponta que maiores níveis de governança corporativa auxiliam na mitigação de problemas de agências e, consequentemente, de assimetria informacional.

\subsection{Análise dos PAAs e segmentos econômicos}

No que tange à análise dos segmentos econômicos e os PAAs reportados, pode-se observar na Figura 5 que, de forma geral, os segmentos que mais emitiram parágrafos de auditoria foram Utilidade Pública e Financeiro, enquanto os que menos emitiram PAAs foram Consumos Não Cíclicos e Bens Industriais. De forma complementar, os PAA's que foram reportados por empresas de todos os segmentos econômicos foram: Contingências (CONT), Reconhecimento de receitas (REC), Recuperabilidade dos ativos (RECU), Participação societária (PART) e outros assuntos (OU). No entanto, as empresas classificadas no segmento de Bens Industriais não emitiram PAAs sobre projeção de resultados futuros, controles internos/tecnologia da informação, riscos relacionados à conformidade de normas e regulamentos e benefícios pós-emprego. Por sua vez, as empresas de Consumo Cíclico só não emitiram PAAs a respeito de projeção de resultados futuros. Já as companhias de Consumo Não Cíclico não se posicionaram acerca de capitalização de gastos no ativo, benefícios pós-emprego e processos administrativos. 


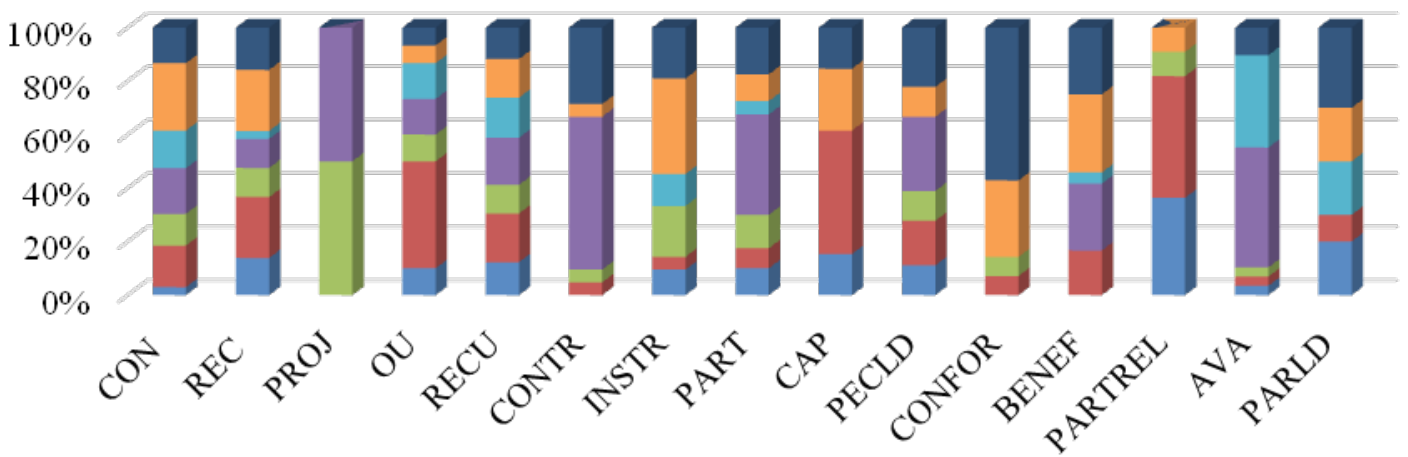

\begin{abstract}
Bens Industriais
- Consumo Cíclico

- Consumo Não Cíclico $\square$ Financeiro e Outros

- Materiais Básicos

- Utilidade Pública

- Utilidade Pública

Nota: AVA - Ativos biológicos/Valor justo/Ágio; BENEF - Benefícios pós-emprego; CAP - Capitalização de gastos no ativo; CON - Contingências; CONFOR - Riscos relacionados à conformidade com leis e regulamentos; CONTR - Controles internos e tecnologia da informação; INSTR - Instrumentos financeiros; PARLD - Processos administrativos instaurados/Recuperação judicial/Distratos; PART - Participação societária; PARTREL - Partes relacionadas; PECLD - Provisão para créditos de liquidação duvidosa; PROJ - Projeção de resultados futuros para a realização de ativos; REC - Reconhecimento de receitas; RECU Recuperabilidade dos ativos; e OU - Outros.
\end{abstract}

Figura 5. Frequência de PAAs e Segmento econômico

Fonte: dados da pesquisa

Especificamente as empresas do setor Financeiro apresentaram 10 dos 15 tipos de PAAs, tendo maior destaque nos assuntos de Controles Internos e Tecnologia da Informação (CONTR), Projeção de Resultados Futuros para Realização de Ativos (PROJ), Ativos Biológicos/Valor Justo/Ágio (AVA), Participação Societária (PART) e Provisão para Créditos de Liquidação Duvidosa (PECLD). Ademais, companhias classificadas no setor de Materiais Básicos seguiram sendo um dos segmentos que mais reportaram, não se posicionando somente acerca de projeção de resultados futuros (PROJ), controles internos (CONTR), capitalização de gastos no ativo (CAP), clientes duvidosos (PECLD, conformidades (CONFOR) e partes relacionadas (PARTREL). Por último, entidades classificadas como de Utilidade Pública não emitiram PAAs sobre projeções futuras e avaliações a valor justo. Todas essas considerações alinham-se ao estudo de Marques e Souza (2017), em que os autores reforçam a atenção exigida dos auditores, uma vez que se tratam de pontos críticos diretamente ligados aos julgamentos dos gestores em relação às escolhas contábeis.

\title{
4.3 Análise da associação entre os PAAs e o gerenciamento de resultados por accruals e operacional
}

De modo a se verificarem os quatro modelos de gerenciamento de resultados anteriormente apresentados, estimaram-se as proxies de gerenciamento de resultados por meio de regressão com dados em painel, com efeitos aleatórios nos modelos (1), (2) e (4), enquanto usaram-se efeitos fixos no modelo (3). Conforme os resultados do Modelo (1) da Tabela 2, observa-se uma relação positiva e significativa estatisticamente $(\mathrm{p}<0,01)$ entre os PAAs e os accruals discricionários (conforme o modelo de Kothari, Ramanna, \& Skinner, 2010), evidenciando que empresas com maiores quantidades de PAAs apresentam maiores níveis de acumulações discricionárias. Esse resultado é coerente com o entendimento de divulgação dos PAAs, uma vez que estes sinalizam o risco do auditor associado às demonstrações contábeis, além de a maioria dos PAA's reportados pelas empresas da amostra apresentarem referência a eventos relacionados a estimativas e/ou receitas, ambos os pontos abordados como passíveis de gerenciamento de resultados (Marques \& Souza, 2017). 
Tabela 2

Estatística dos modelos de gerenciamento de resultados testados

\begin{tabular}{|c|c|c|c|c|c|}
\hline & S.E. & Accruals & FCODiscr & DespDiscr & RecDiscr \\
\hline & & (1) & $(2)$ & (3) & (4) \\
\hline \multirow[t]{2}{*}{ Intercepto } & $?$ & $0.187^{*}$ & $-0.409 * * *$ & 0.0732 & 0.0779 \\
\hline & & $(0.0974)$ & $(0.112)$ & $(0.100)$ & $(0.0760)$ \\
\hline \multirow[t]{2}{*}{ LnPAA's } & + & $0.0667 * * *$ & -0.0126 & $-0.0340 * *$ & 0.0534 *** \\
\hline & & $(0.0118)$ & $(0.0235)$ & $(0.0149)$ & $(0.00978)$ \\
\hline \multirow[t]{2}{*}{ LnRem } & $+/-$ & -0.00176 & 0.000758 & 0.00761 * & 0.00295 \\
\hline & & $(0.00347)$ & $(0.0104)$ & $(0.00401)$ & $(0.00389)$ \\
\hline \multirow[t]{2}{*}{ NivEnd } & + & 0.0193 & $-0.145^{* * *}$ & 0.0746 *** & $0.0639 * *$ \\
\hline & & (0.0299) & $(0.0281)$ & $(0.00965)$ & $(0.0290)$ \\
\hline \multirow[t]{2}{*}{ Tam } & + & $-0.0107 * * *$ & $0.0172 *$ & -0.00472 & $-0.0106 * * *$ \\
\hline & & $(0.00351)$ & $(0.00885)$ & $(0.00312)$ & $(0.00267)$ \\
\hline \multirow[t]{2}{*}{ ROA } & - & $0.306 * * *$ & $-0.139 * * *$ & -0.0125 & $0.185^{\star * *}$ \\
\hline & & $(0.0910)$ & $(0.0343)$ & $(0.0476)$ & $(0.0574)$ \\
\hline \multirow[t]{2}{*}{$\mathrm{Ri}$} & - & -0.0159 & $-0.0299 * *$ & $0.0351 * * *$ & 0.0226 \\
\hline & & $(0.0156)$ & $(0.0127)$ & $(0.00973)$ & $(0.0159)$ \\
\hline \multirow[t]{2}{*}{ EstrProp } & + & $-0.000377 * * *$ & $2.04 \mathrm{e}-06$ & -0.000129 & -0.000113 \\
\hline & & $(0.000101)$ & $(0.000169)$ & $(0.000271)$ & $(0.000126)$ \\
\hline Modelo & & EA & $\mathrm{EF}$ & EA & EA \\
\hline Wald $x^{2}$ & & $367.35 * * *$ & $79.10 * * \star$ & $819.53 * * *$ & $73.19 * * *$ \\
\hline Observações & & 130 & 130 & 130 & 130 \\
\hline $\mathrm{R}^{2}$ Geral & & 0.6027 & 0.191 & 0.2973 & 0.3982 \\
\hline Seg.Econ. & & 9 & 9 & 9 & 9 \\
\hline
\end{tabular}

Nota: erros padrões robustos em parênteses *** $p<0.01$, ** $p<0.05$, * $p<0.1$. EstrProp - Percentual de participação do maior acionista; LnRem - Logaritmo natural da remuneração dos executivos no período. NivEnd - Total do passivo dividido pelo total do ativo; PAA's - Logaritmo dos PAA's reportados; Ri - Retorno de mercado calculado pelo logaritmo da divisão entre o valor de mercado corrente e o anterior das empresas; ROA - retorno sobre os Ativos calculado a partir do Lucro líquido dividido pela média dos ativos; e Tam - Logaritmo natura 1 do ativo total das empresas. As variáveis Big4, NivGove SegEcon foram omitidas, pois não apresentaram significância estatística. Realizaram-se os testes: Chow (Pooledvs Efeitos Fixos), BreushPagan (Pooledvs Efeitos Aleatórios) e Hausman (Efeitos fixos vs Efeitos Aleatórios), nessa ordem. Mod.1 Chow [Prob> F $=0.9510]$; Breush Pagan [Prob $\left.>x^{2}=1.0000\right]$; Hausman [Prob $\left.>x^{2}=0.9659\right]$. Mod. $2-$ Chow [Prob $\left.>F=0.0166\right] ;$ Breush Pagan [Prob $\left.>x^{2}=1.0000\right]$; Hausman [Prob $>x^{2}=0.0003$ ]. Mod.3 - Chow [Prob $\left.>F=0.0290\right]$; Breush Pagan [Prob $>x^{2}$ $=1.0000]$; Hausman [Prob $\left.>x^{2}=0.0509\right]$. Mod. 4 -Chow $[$ Prob $>F=0.1219] ;$ Breush Pagan $\left[\right.$ Prob $\left.>x^{2}=1.0000\right]$; Hausman $\left[\right.$ Prob $\left.>x^{2}=0.9830\right]$.

Além disso, ao analisar o Modelo 1, apresentado na primeira coluna da Tabela 2, observa-se uma relação negativa e estatisticamente significativa $(\mathrm{p}<0,01)$ entre o tamanho (Tam) e os accruals discricionários, indicando que empresas com maior ativo total tendem a apresentar menores níveis de gerenciamento de resultados por accruals, sugerindo que essas tendem a ter maior qualidade das informações contábeis (Badolato, Donelson, \& Ege, 2014). Quanto ao resultado do Retorno sobre os Ativos, verificou-se que empresas com maiores ROAs são propensas a apresentar menor gerenciamento de resultados por accruals. Além disso, verificou-se um efeito negativo entre a variável de Estrutura de Propriedade e o gerenciamento por accruals, que pode ser explicado, de acordo com Alzoubi (2016), pelo fato de que empresas com maiores concentrações de propriedade tendem ao maior monitoramento por acionistas minoritários e órgãos reguladores. Por outro lado, observa-se que as maiores empresas apresentam maiores níveis de discricionariedade do FCO. 
A análise do Modelo 2, na segunda coluna da Tabela 2, evidencia que a variável PAA não apresentou significância estatística, embora sugira uma relação negativa com o gerenciamento de resultados pelas operações através do FCO, indicando que os relatórios de auditoria podem minimizar o comportamento oportunista dos gestores em manipular os resultados por meio dos fluxos de caixa operacionais. Entretanto, o modelo demonstrou que empresas mais endividadas, com maiores retornos de mercado (Ri) e sobre os ativos (ROA), apresentam menores níveis de discricionariedade do FCO. Esse resultado converge com a expectativa teórica, pois a variabilidade do FCO afeta a percepção de risco por parte dos investidores, gerando perda de valor da empresa. Desse modo, os gestores possuem incentivos para não gerenciarem o resultado pelo FCO (Kothari, Leone, \& Wasley, 2005).

Quanto aos resultados do Modelo 3 da Tabela 2, que analisa as despesas discricionárias, observa-se uma relação negativa e estatisticamente significativa $(\mathrm{p}<0,05)$ com os PAAs, podendo ser explicada pelo fato de que os auditores são orientados pelo conservadorismo contábil a priorizar o reconhecimento de despesas contábeis antes das despesas da mesma categoria (Paulo, Antunes, \& Formigoni, 2008). Além disso, a variável de remuneração dos executivos apresentou uma relação positiva e estatisticamente significativa $(\mathrm{p}<0,1)$ com as despesas discricionárias, indicando que quanto maior o pacote de remuneração, maior a discricionariedade das despesas, evidenciando certa fragilidade dos pacotes de remuneração em termos de mitigação de problemas de agência e fidedignidade das informações financeiras (Ali \& Kumar, 1993). No que se refere à relação entre o nível de endividamento e as despesas discricionárias, o efeito positivo e estatisticamente significante $(\mathrm{p}<0.01)$ indica que quanto maior o nível de endividamento da empresa, maiores serão suas despesas discricionárias. Contabilmente, essa relação pode ser explicada por meio da concessão de descontos e de outras estratégias que são voltadas à recuperação econômico-financeira da empresa (Cupertino, Martinez, \& Costa Jr, 2016).

Observou-se, na análise do Modelo 4, uma relação estatisticamente significativa e positiva entre os PAAs e as Receitas Discricionárias (RecDiscr), indicando que quanto maior a emissão de parágrafos de auditoria, maiores serão as receitas discricionárias, apresentando indícios de gerenciamento de resultados operacionais. Considerando os principais tipos de PAAs reportados (Figura 2), tal resultado mostrase coerente, dado que evidencia uma preocupação dos auditores com áreas em que existem potenciais para a ocorrência de manipulação de informes financeiros. Especificamente, os resultados reforçam a necessidade de monitoramento consistentemente das contas de receitas, na medida em que aquelas empresas que reportam mais PAAs tendem a apresentar maior discricionariedade das receitas, uma proxy de gerenciamento de resultados pelas operações. A variável de nível de endividamento apresentou uma relação positiva e estatisticamente significativa $(\mathrm{p}<0,05)$, evidenciando que empresas com maiores graus de endividamento tendem a adotar medidas de aumento de receitas contábeis, reduzindo, assim, a avaliação do risco de quebra de cláusulas contratuais de dívidas, conforme estudado por Mosebach e Simko (2010). De forma similar ao observado no Modelo 1, a relação negativa entre a variável Tamanho indica que as maiores empresas apresentam menores níveis de gerenciamento de resultados por receitas discricionárias. Por fim, a variável ROA apresentou uma relação estatisticamente significativa ( $\mathrm{p}<0,01)$, permitindo inferir que empresas com maiores retornos sobre ativos tendem a gerenciar resultados por meio das receitas discricionárias, corroborando o pressuposto de que valores sobrestimados da receita tendem a resultar em maior lucratividade e, consequentemente, impactar o índice. 


\section{Considerações Finais}

Este estudo buscou investigar a relevância da evidenciação da opinião do auditor em parágrafo específico, seguindo normas NBA TA 701, e o quanto essa opinião influencia a utilização de mecanismos de gerenciamento de resultados. Tal avaliação se torna significativa, uma vez que a aprovação da norma citada orienta os auditores a evidenciarem quais foram os principais assuntos de auditoria durante o processo de revisão das demonstrações contábeis das companhias de capital aberto. O estudo, de natureza descritiva, documental e com abordagem quantitativa analisou dados referentes ao período de 2016 e 2017, dois primeiros anos de vigência da NBA TA 701, das 96 empresas que compuseram a carteira teórica IBRX100 da $[\mathrm{B}]^{3}$. A análise foi realizada por meio da estatística descritiva e da análise de regressão crosssection para os modelos de painel para o modelo econométrico proposto, buscando analisar o efeito desses parágrafos específicos sobre as proxies de gerenciamentos de resultados.

Em relação à quantidade de PAAs que foram emitidos pelos auditores, os resultados evidenciaram que, para a amostra selecionada, há em média 3,49 PAA's por empresa no ano de 2016 e 3,30 PAAs por empresa para os demonstrativos de 2017, mostrando uma pequena redução do número de especificidades apontadas pelos auditores. Os PAAs mais reportados foram: (i) Recuperabilidade dos ativos (RECU), (ii) Contingências (CON) e (iii) Reconhecimento de receitas (REC), representando em torno de $62 \%$ dos PAAs emitidos no período analisado. Observou-se, ainda, que as empresas não Big4 reportaram mais PAAs quando comparadas às empresas de auditoria consideradas Big4. Além disso, as empresas dos setores de Utilidade Pública e do ramo Financeiro foram as que mais emitiram PAAs. Já as empresas do Novo Mercado apresentaram menor quantidade de PAAs reportados. Esses resultados estão sensivelmente alinhados aos verificados no estudo de Marques \& Souza (2017).

No que se refere à relação entre o número de PAAs emitidos e as proxies de gerenciamento de resultados, três dos quatro modelos indicaram relação estatisticamente significativa entre as variáveis. Os modelos de accruals discricionários e de receitas discricionárias evidenciaram uma relação positiva e estatisticamente significativa a um nível de $1 \%$, evidenciando que empresas que reportam mais PAAs tendem a apresentar maior nível de gerenciamentos de resultados. Já, no modelo de despesas discricionárias, verificou-se uma relação negativa e estatisticamente significativa a 5\%, o que indica que empresas com maior quantidade de PAAs reportados tendem a apresentar menores níveis de despesas discricionárias. Já em relação à associação positiva entre a quantidade de PAAs, os accruals e as receitas discricionárias, os resultados estão ajustados, dado que os assuntos mais reportados pelos auditores foram aqueles que poderiam indicar algum tipo de manipulação da informação contábil, tais quais "Recuperabilidade dos Ativos" (RECU), "Contingências" (CONT) e "Reconhecimento de Receitas" (REC). Por outro lado, o maior reporte de PAAs sugere mitigar a discricionariedade por gestores em evidenciar possíveis riscos de distorções das informações contábeis.

Além disso, considerando o conceito de CAM - Critical Audit Matters, em nossa tradução, PAAs, emitido pelo Public Company Accounting Oversight Board(PCAOB), Gimbar et al. (2016) afirmam que esses assuntos críticos poderiam ser interpretados como isenção de responsabilidade do auditor pelas partes mais subjetivas das demonstrações financeiras, que estão além de seu controle razoável. Essa discussão corrobora os achados deste estudo, conforme explicitado, em que o número de PAAs reportados apresentou relação positiva e significativa com as variáveis Accruals e Receitas Discricionárias, ou seja, itens que, devido à discricionariedade, podem ser reconhecidos nas demonstrações financeiras de acordo com o julgamento do agente - gestor da entidade -, influenciando seu resultado e aumentando a possibilidade de se caracterizar como um assunto crítico e/ou subjetivo, de acordo com o ceticismo e julgamento profissional do auditor, o que, por conseguinte, deve ser comunicado ao comitê de auditoria. 
Os resultados devem considerar as conclusões de Chen, Hsu, Huang \& Yang (2013) e de Church, Davis e McCracken (2008), em que os autores argumentam que quanto mais informações dispostas nos Relatórios Financeiros, menor a sua relevância, uma vez que os stakeholders não interpretam os elementos informacionais em sua totalidade. Entretanto, na amostra estudada, verifica-se que a análise dos PAAs reportados pode contribuir para as partes interessadas, dadas as associações observadas, reforçando a relevância de tal divulgação. Segal (2017) destaca que, ao evidenciarem os procedimentos mais relevantes relacionados aos controles internos das empresas, os auditores podem indiretamente demonstrar quais são os procedimentos mais falhos, gerando desconfiança por parte de potenciais investidores.

Como apontado por Coram, Mock, Turner \& Gray (2011), observa-se uma preocupação dos órgãos reguladores em melhorar a qualidade de informação dos Relatórios Contábeis ao aproximar as ênfases dos auditores nos parágrafos destinados a essas opiniões, mantendo uma avaliação crítica sobre os resultados práticos desse tipo de elaboração de opinião em parágrafo específico. Nesse sentido, o estudo sugere que os auditores, reguladores e demais órgãos de controle devem reforçar a política de divulgação dos PAAs e, principalmente, monitorar sua associação com indícios de manipulação das informações contábeis, sendo esse um fenômeno que subverte o objetivo da contabilidade, prejudicando a fidedignidade das informações financeiras.

O estudo buscou trazer evidências empíricas sobre a associação entre os PAAs e as proxies de gerenciamento de resultados. Os resultados desta pesquisa contribuem parcialmente com a literatura nacional sobre o assunto, considerando que a norma tratada é recente e os estudos empíricos são incipientes (Marques \& Souza, 2017). Também é possível notar a contribuição desta pesquisa a auditores e reguladores em geral, na medida em que evidencia que os PAAs estejam associados ao gerenciamento de resultados. Dessa forma, o histórico de reporte da companhia pode ser um red flag (sinalizador de risco) importante para esses agentes ao considerarem a qualidade informacional da companhia.

Apesar das contribuições e implicações mencionadas, o estudo apresenta limitações quanto ao tamanho da amostra, o período estudado e a modelagem utilizada. Desse modo, sugere-se para futuras pesquisas a utilização de outras modelagens e modelos de gerenciamento de resultados, ou, ainda, verificar a associação entre os PAAs e as deficiências de controles internos reportadas. Outra sugestão é verificar se, ao longo do tempo, as empresas reportam PAAs diferentes, ou não, de forma a investigar se os problemas mencionados pelos auditores persistem na operacionalidade das companhias. Por fim, sugere-se analisar se existe associação entre a divulgação de PAA's com o tipo de opinião do auditor, os honorários de auditoria, a troca de auditor e a qualidade da auditoria.

\section{Referências}

Ali, A. \& Kumar, R. (1993). Earnings Management Under Pension Accounting Standards: SFAS 87 versus APB 8. Journal of Accounting, Auditing \& Finance, 8(4), pp. 427-446. doi: $10.1177 / 0148558$ X9300800405

Almeida, J., \& Almeida, J. (2009). Auditoria e earnings management: estudo empírico nas empresas abertas auditadas pelas Big Four e demais firmas de auditoria. Revista Contabilidade \& Finanças, 20(50), 62-74. doi: 10.1590/S1519-70772009000200005

Alzoubi, E. S. S. (2016). Audit quality and earnings management: evidence from Jordan. Journal of Applied Accounting Research, 17(2), pp. 170-189. doi:10.1108/jaar-09-2014-0089

Arruñada, Benito, Protestants and Catholics: Similar Work Ethic, Different Social Ethic (September 3, 2010). The Economic Journal, 2010, 120(547), 890-918. Available at SSRN: https://ssrn.com/ abstract=1397223 or http://dx.doi.org/10.2139/ssrn.1397223 
Badolato, P. G., Donelson, D. C. \&Ege, M. (2014).Audit committee financial expertise and earnings management: the role of status. Journal of Accounting and Economics, 58(2), pp. 208-230. doi: 10.1016/j.jacceco.2014.08.006

Badertscher, B. A. (2011). Overvaluation and the Choice of Alternative Earnings Management Mechanisms. The Accounting Review, 86(5), pp. 1491-1518. doi:10.2308/accr-10092

Barth, M. E., Landsman, W. R \& Lang, M. H. (2008).International Accounting Standards and Accounting Quality. Journal of Accounting Research, 46(3), pp. 467-498. doi:10.1111/j.1475-679X.2008.00287.x

Becker, C. L., Defond, M. L., Jiambalvo, J., \& Subramanyam, K. R. (1998). The Effect of Audit Quality on Earnings Management. Contemporary Accounting Research, 15(1), pp.1-24. doi:10.1111/j.1911-3846.1998.tb00547.x

Bédard, J., Besacier, N., \& Schatt, A. (2014, January). Costs and Benefits of Reporting Key Audit Matters in the Audit Report: The French Experience. Recuperado de https://www.isarhq.org/2014 downloads/papers/ISAR2014_Bedard_Besacier_Schatt.pdfBeattie, V., Fearney, S., Brandt, R. (2000). Behind the audit report: a descriptive study of discussion and negotiation between auditors and directors. International Journal of Auditing, 4(2), pp.177-202. doi: 10.1111/1099-1123.00312

Beaver, W. H. (1998). Financial Reporting: an accounting revolution. ( ${ }^{\text {rd }}$ edn). Upper Saddle River, NJ: Prentice-Hall

Boolaky, P., \& Omoteso, K. (2016). International standards on auditing in the international financial services centres: What matters? Managerial Auditing Journal, 31(6/7), pp. 727-747. doi: 10.1108/ MAJ-09-2015-1243

Brasel, K., Doxey, M., Grenier, J., \& Reffett, A. (2016). Risk Disclosure Preceding Negative Outcomes: The Effects of Reporting Critical Audit Matters on Judgments of Auditor Liability. The Accounting Review, 91(5), pp. 1345-1362. doi:10.2308/accr-51380.

Brickley, J. A., Smith, C. W. \& Zimmerman, J. L. (2016). Managerial Economics and Organizational Architecture. ( $6^{\text {th }}$ ed.) McGraw-Hill.

Brown, P., Beekes, W.\& Verhoeven, P. (2011). Corporate governance, accounting and finance: A review. Accounting \& Finance, 51(1), pp. 96-172. doi: 10.1111/j.1467-629X.2010.00385.x

Chen, Y., Hsu, J., Huang, M. \& Yang, P. (2013). Quality, size, and performance of audit firms. International Journal of Business and Finance Research. 7(5), pp. 89-105. Recuperado de http://www.theibfr2.com/ RePEc/ibf/ijbfre/ijbfr-v7n5-2013/IJBFR-V7N5-2013-8.pdf

Choi, J.H.\& Wong, T.J. (2007) Auditors' Governance Functions and Legal Environments: An International Investigation. Contemporary Accounting Research, 24(1), pp.13-46. doi: 10.1506/X478-10754PW5-1501

Church, B. K., Davis, S. M.\&McCracken, S. A. (2008) The auditor's reporting model: a literature overview and research synthesis. Accounting Horizons.22(1), pp.69-90.doi: 10.2308/acch.2008.22.1.69

Cohen, J. R.; Krishnamoorthy, G. \& Wrigth, A. (2004).The corporate Governance Mosaic and Financial Reporting Quality. Journal of Accounting Literature, pp. 87-152. Recuperado de file://C:/Users/ rejane/Downloads/SSRN-id1086743.pdf

Cohen, D. A., \& Zarowin, P. (2010). Accrual-based and real earnings management activities around seasoned equity offerings. Journal of Accounting and Economics, 50(1), pp. 2-19. doi:10.1016/j. jacceco.2010.01.002

Conselho Federal De Contabilidade. Norma NBC TA 701 - Comunicação dos Principais Assuntos de Auditoria no Relatório do Auditor Independente. Brasília, 04 de julho de 2016. Recuperado de https://cfc.org.br/tecnica/normas-brasileiras-de-contabilidade/nbc-ta-de-auditoria-independente/ 
Colares, A.C.V., Alves, K.C. \& Pinheiro, L.E.T. (2018). Efeitos da Divulgação dos Principais Assuntos de Auditoria no Retorno das Ações no Mercado de Capitais Brasileiro. IX Congresso Brasileiro de Administração e Contabilidade - AdCont 201824 a 26 de outubro de 2018 - Rio de Janeiro, RJ. Recuperado de http://adcont.net/index.php/adcont/adcont2018/paper/viewFile/2992/836

Coram, P. J., Mock, T. J., Turner, J. L. \& Gray, Gl L. (2011) The communicative value of the auditor's report. Australian Accounting Review, 21(3), pp. 235-252. doi: 10.1111/j.1835-2561.2011.00140.x

Cupertino, C,Martinez, A. \& Costa Jr, N. (2016). Consequências para a rentabilidade futura com o gerenciamento de resultados por meio de atividades operacionais reais. Revista Contabilidade \& Finanças, 27(71), 232-242 doi: 10.1590/1808-057x201602520

Dantas, J., Barreto, I., \& Carvalho, P. (2017). Relatório com modificação de opinião: risco para o auditor?. Revista Contemporânea de Contabilidade, 14(33), 140-157. doi:10.5007/2175-8069.2017v14n33p140

Dechow, P. M., Sloan, R. G. \& Swenney, A. P. (1995). Detecting Earnings Management. The Accounting Review. 70(2), pp. 193-225.

Dechow, P. M. \&Skinner, D. J. (2000). Earnings management: Reconciling the views of accounting academics, practitioners, and regulators. Accounting Horizons, 14(2), pp.235-250. doi: 10.2308/ acch.2000.14.2.235

Dichev, I. D. \& Skinner, D. J. (2002) Large-Sample Evidence on the Debt Covenant Hypothesis. Journal of Accounting Research, 40(4), pp. 1091-1123. doi: 10.1111/1475-679X.00083

Di Pietra, R., McLeay, S., \& Ronen, J. (2014). Accounting and Regulation: new insigths on governance, markets and institutions. New York: Springer. doi: 10.1007/978-1-46148097-6

Fama, E. (1970). Efficient Market: A review of theory and empirical work. Journal of Economics, 14, 383417.

Gaver, J., Gaver K., \& Austin, J. (1995). Additional Evidence of Bonus Plans and Income Management. Journal of Accounting and Economics, 19(1), pp. 3-28. doi: 10.1016/0165-4101(94)00358-C

Gimbar, C., T. B. Hansen, \& M. E. Ozlanski, (2016). The Effects of Critical Audit Matter Paragraphs and Accounting Standard Precision on Auditor Liability. The Accounting Review, 91(6), pp.1629-1646. doi 10.2308/accr-51382.

HassabElnaby, H. R. (2006). Waiving Technical Default: The Role of Agency Costs and Bank Regulations. Journal of Business Finance \& Accounting, 33(9-10), pp.1368-1389. doi:10.1111/j.14685957.2006.00633.x.

Ishikawa, M., Bezerra Júnior V. A. (2002). Responsabilidade e o Papel da Auditoria Independente de Demonstrações Contábeis. IX Congresso Brasileiro de Custos - São Paulo, SP, Brasil, 13 a 15 de outubro de 2002. Recuperado de file:///C:/Users/rejane/Downloads/2680-2680-1-PB.pdf

Jensen, M. C.\& Meckling, W. H. (1976) Theory of the firm: managerial behavior, agency costs and ownership structure. Journal of Financial and Economics, 3(4), pp. 305- 360. doi: 10.1016/0304-405X(76)90026-X

Jensen, M. C. \& Meckling, W. H. (1994). The nature of man. Journal of Applied Corporate Finance, 7(2), pp. 4-19. doi: 10.1111/j.1745-6622.1994.tb00401.x

Kauhanen, A., \& Napari, S. (2012). Performance Measurement and Incentive Plans. Industrial Relations: A Journal of Economy and Society, 51(3), pp.645-669. doi:10.1111/j.1468-232x.2012.00694.x

Kim, Y., Liu, C. \& Rhee, S. G. (2003). The relation of earnings management to firm size (Working paper). University of Hawaii. Recuperado de http://citeseerx.ist.psu.edu/viewdoc/download?doi=10.1.1.2 $00.9183 \&$ rep $=$ rep $1 \&$ type $=$ pdf

Kothari, S. P., Leone, A. J., \& Wasley, C. E. (2005). Performance matched discretionary accrual measures. Journal of Accounting and Economics, 39(1), pp.163-197. doi:10.1016/j.jacceco.2004.11.002 
Kothari, S. P., Ramanna, K., \& Skinner, D. J. (2010). Implications for GAAP from an analysis of positive research in accounting. Journal of Accounting and Economics, 50(2-3),pp.246-286. doi:10.1016/j. jacceco.2010.09.003.

Leuz, C.; Nanda, D.; Wysocki, P. D. (2003). Earnings management and investor protection: an international comparison. Journal of Financial Economics, 69(3), pp.505-527. doi: 10.1016/S0304405X(03)00121-1

Lewellen, W. G. \& Rosenfeld, A. (1987) Optimal bond refunding strategies. Managerial and Decision Economics, 8(3), pp.243-250. doi: 10.1002/mde.4090080311

Marques, V.A.; Souza, M. K. P. (2017). Principais assuntos de auditoria e opinião sobre o risco de descontinuidade: uma análise das empresas do Ibovespa. Revista de Informação Contábil,11(4), 1-22. Recuperado de file://C:/Users/rejane/Downloads/230107-77036-1-PB.pdf

Makar, S. D., \& Alam, P. (1998). Earnings Management and Antitrust Investigations: Political Costs Over Business Cycles. Journal of Business Finance Accounting, 25(5\&6), 701-720. doi:10.1111/14685957.00208

Matos, T., Santos, O., Rodrigues, A., \& Leite, R. (2018). Lobbying na regulação de auditoria no âmbito do IAASB. Revista Contabilidade \& Finanças, 29(77), pp. 246-265. doi: 10.1590/1808-057x201804330

Mosebach, M. \& Simko, P. (2010).Discretionary Accruals and the emergence of profitability. Journal of Accounting, Auditing \& Finance, 25(3), 351-374. doi: 10.1177/0148558X1002500304

Paulo, E. (2007). Manipulação das informações contábeis: uma análise teórica e empírica sobre os modelos operacionais de deteç̧ão de gerenciamento de resultados. Tese de Doutorado, Faculdade de Economia, Administração e Contabilidade, Universidade de São Paulo, São Paulo. doi:10.11606/T.12.2007.tde28012008-113439.

Paulo, E.;Antunes, M. T. P.\& Formigoni, H. (2008 - Julho/Setembro). Conservadorismo Contábil nas Companhias Abertas e Fechadas Brasileiras. Revista de Administração de Empresas, 48(3), pp. 4660. doi: 10.1590/S0034-75902008000300005

Queiroz, J. \& Almeida, J. (2017 - Julho/Setembro). Efeitos das Hipóteses da Teoria Positiva da Contabilidade na qualidade da informação contábil. Revista Universo Contábil, 13(3), 50-69. doi: 10.4270/ruc.20173\%p. Recuperado de https://www.redalyc.org/pdf/1170/117054197004.pdf

Rodrigues, R. M., Paulo, E. \& Melo, C. L. (2017 - Setembro/Dezembro). Gerenciamento de Resultados por decisões operacionais para sustentar desempenho nas empresas não-financeiras do Ibovespa. Contabilidade Vista \& Revista, 28(3), pp. 82-102. Recuperado de file://C:/Users/rejane/ Downloads/3729-Texto\%20do\%20artigo-17061-1-10-20180328.pdf

Ross, S. (1973) The Economic Theory of Agency: The Principal's Problem. The American Economic Review, 63(2), pp. 134-139. Recuperado de file://C:/Users/rejane/Downloads/ TheEconomicTheoryofAgency-ThePrincipalsProblem.pdf

Roychowdhury, S. (2006). Earnings management through real activities manipulation. Journal of Accounting and Economics, 42(3), pp. 335-370. doi:10.1016/j.jacceco.2006.01.002

Scott, William R. (2011). Financial Accounting Theory. (6. ed.) Toronto: Pearson Education.

Segal, M. (2017). ISA 701: Key audit matters - An exploration of the rationale and possible unintended consequences in a South African. Journal of Economic and Financial Sciences. 10(2), 376-391. doi: 10. 376-391. 10.4102/jef.v10i2.22.

Setyorini, C. T. \& Ishak, Z. (2012). Corporate social and environmental disclosure: A positive accounting theory view point. International Journal of Business and Social Science, 3(9), 152-162. Recuperado de https://pdfs.semanticscholar.org/5393/41a726d17ca827fc0f39e5ebfd0100110042.pdf?_ $\mathrm{ga}=2.48925030 .1329175991 .1581628327-401073071.1581106557$ 
Sincerre, B.; Sampaio, J.;Famá, R.\& Santos, J. (2016 - Setembro/Dezembro). Emissão de dívida e gerenciamento de resultados. Revista Contabilidade \& Finanças, 27(72), pp.291-305. doi: /10.1590/1808-057x201601660

Sonza, I. B. \& Kloeckner, G. O. (2014 - Maio/Agosto). A Governança Corporativa Influencia a Eficiência das Empresas Brasileiras?. Revista Contabilidade \& Finanças, 25(65), pp. 145-160. doi: 10.1590/ S1519-70772014000200005

Vladu, A. B., Amat, O. \& Cuzdriorean, D. D. (2017). Truthfulness in accounting: How to discriminate accounting manipulators from non-manipulators. Journal of Business Ethics, 140(4), pp. 633-648. doi: 10.1007/s10551-016-3048-3

Watts, R. L. \& Zimmerman, J. L. (1986). Positive accounting theory. Upper Saddle River: Prentice Hall.

Williamson, O. E. (1979). Transaction cost economics: the governance of contractual relations. Journalof Law and Economics, 22(2), 233-261. Recuperado de https://pdfs.semanticscholar.org/ c982/727420ca620043ce8aa1b8865d00755a984d.pdf

Zang, A. Y. (2012). Evidence on the Trade-Off between Real Activities Manipulation and Accrual-Based Earnings Management. The Accounting Review, 87(2), pp. 675-703. doi:10.2308/accr-10196 